\title{
Fish Nutrition Additives in SHK-1 Cells: Protective Effects of Silymarin
}

\author{
Rodrigo Sanchez ${ }^{1,2 *}$, Pamela Olivares ${ }^{1 *}$, Erico Carmona ${ }^{3}$, Allisson Astuya ${ }^{4}$, \\ Hector Herrera², Jorge Parodi1\# \\ ${ }^{1}$ Laboratorio Fisiología de la Reproducción, Escuela de Medicina Veterinaria, Núcleo de Investigación en \\ Producción Alimentaria, Facultad de Recursos Naturales, Universidad Católica de Temuco, Temuco, Chile \\ ${ }^{2}$ Empresa Vitapro Chile, Castro, Región de Los Lagos, Chile \\ ${ }^{3}$ Grupo de Genotoxicología, Escuela de Medicina Veterinaria, Núcleo de Estudios Ambientales, Facultad de \\ Recursos Naturales, Universidad Católica de Temuco, Temuco, Chile \\ ${ }^{4}$ Laboratory of Cell Culture and Marine Genomics, Marine Biotechnology Unit, Faculty of Natural and \\ Oceanographic Sciences, University of Concepcion and Sur-Austral COPAS Program, University of Concepcion, \\ Concepción, Chile \\ Email: \#jparodi@uct.cl
}

Received 9 January 2016; accepted 15 February 2016; published 18 February 2016

Copyright (C) 2016 by authors and Scientific Research Publishing Inc.

This work is licensed under the Creative Commons Attribution International License (CC BY). http://creativecommons.org/licenses/by/4.0/

(c) (i) Open Access

\begin{abstract}
In nutrition for productive species, additives play an important role in boosting physiological processes. Only in recent years studies include models of the effects on fish cells of these additives. We observed effects of silymarin, a compound highly utilized in aquaculture. The cell line SHK-1 was used derived from the upper liver of the Atlantic salmon as a biological model. Samples were exposed to silymarin in incrementing time and concentrations, to evaluate by MTT and number of cells, the effects on cell viability. Also, oxidative stress models were used to find the protector effects of silymarin against these agents. Our data indicate that a dose of $\mathbf{1 0 0} \mathbf{~ p p m}$ of silymarin is sufficient to stimulate cellular proliferation. Cultures were exposed to high glucose $(15 \mathrm{mM})$ or $\mathrm{H}_{2} \mathrm{O}_{2}(0.1 \mathrm{mM})$ in presence of or absence of silymarin at $100 \mathrm{ppm}$. We observed that the toxic effects of both compounds were blocked by the presence of silymarin. Our results indicate that it is important to evaluate additive effects at a cellular level. Also, silymarin does have proliferative effects, and protect against cellular injury in our models. Our study helps to generate more rational applications of additives in the industry and presents new challenges in order to better manipulate the model in the laboratory, allowing us to obtain new evidence regarding the microalgae's biology through in vitro studies.
\end{abstract}

\footnotetext{
"Both authors contributed in an equal form in the manuscript.
}

"Corresponding author.

How to cite this paper: Sanchez, R., Olivares, P., Carmona, E., Astuya, A., Herrera, H. and Parodi, J. (2016) Fish Nutrition Additives in SHK-1 Cells: Protective Effects of Silymarin. Advances in Bioscience and Biotechnology, 7, 55-62. 


\section{Keywords}

\section{Fish, Nutrition, Silymarin, Cell Cultures}

\section{Introduction}

Cellular cultures are important for fish research and in vertebrates, albeit in the exploration of additives or their interaction with organs and the appearance of secondary effects. Cell cultures also provide unlimited biological material for the diagnostic of alterations produced by additives [1] [2]. Cell lines are study models for molecular effects' con cell function [3]. In vertebrates, especially mammals, they have been amply utilized for biotechnology development, such as the CHO cells [4]. Although it is novel in aquaculture, the passage from information at a cellular level to complex models common in mammals [3]. The most developed compound search is in frog (X. laevis) oocytes, where endogenous receptors are used to understand the pharmacology of nicotine receptors [5]. For this same reason, understanding additive effects at a compound cellular level in fish models is a good option to improve the comprehension of the physiology of them, and avoid toxicity through chronic applications [6] [7]. Silymarin is a complex flavonoligan of Silybum marianum (L.), commonly called thistle, and that comprehends a large number of flavonoligans including Silybin (silybin A and B) isosilybin A and B, silychristin A and $\mathrm{B}$, silydianin and other phenolic compounds [8]. It is amply used in the treatment of hepatic diseases in vertebrates [9] which reduces toxic effect on liver [10] and has effect over hepatic system in fish [11]. Literature suggests that the antioxidant properties of silymarin contribute to its pharmacological properties [12]. But this is not its only exclusive mechanism [13] [14]. Apart from antioxidant properties, it has anti-lipid peroxidative, anti-fibrotic, anti-inflammatory, membrane stabilizing, immunomodulation, as well as anti-tumoral properties, and shows anti-arteriosclerotic and anti-diabetic activity [15] [16]. In fish, the use of silymarin as an antioxidant is not widely studied [17], and it is used in diets as an additive that boosts development and growth [18]. Its use in diets is diverse; it can be used in the farming of freshwater fish [19], or in the fattening of saltwater fish [18]. It has been used as an immunomodulator [15] or a protectant against agents such as curcumin [17], and can regulate function in fish glial cells [20]. Its action mechanism in fish is unknown, and is identified as an additive that is absorbed as a flavonoid through the intestinal wall. Once in the bloodstream, it plays a role in improving cellular nutritional conditions. This could be because of undescribed antioxidant properties, or due to being a metal-chelating agent, improving cell function and development in fishes [15] [17].

In this study, SHK-1 derived cells from the head and kidney of Atlantic salmon were treated in increasing time and concentrations of silymarin. Then, these samples were analyzed by MTT for the number of cells in response to proliferation and their viability. Also, models of oxidative stress were used to measure the protective capacity of silymarin against cells exposed to high levels of glucose.

\section{Methods}

\subsection{Cellular Cultures and Cytotoxic Studies}

Cell lines derived from leucocytes from Salmo salar SHK-1 (ECACC $N^{\circ} 97111106$ ), were maintained in an incubator at $17^{\circ} \mathrm{C}$. Cells were cultivated in a Leibowitz L-15 medium and supplemented with $10 \%$ fetal bovine serum, glutamine $1 \%$, penicillin/streptomycin $1 \%$ and 2-mercaptoetanol $72 \mu \mathrm{l} / \mathrm{ml}$. The cellular expansion procedures were carried out in a biosafety cabinet and then are seed in plates of 24 wells for parallel experiment. Cultures were exposed to temporal curves (one to seven days) and concentrations ( 0.1 to $1000 \mathrm{ppm}$ ) of generic silymarin to evaluate its toxicity, staining and morphology were analyzed to explore the reaction to the additive. Modifying [21], the effect was added of high glucose $30 \mathrm{mM}$ at for 24 hours to generate free radicals, and for seven days to generate an oxidative state. Also, $100 \mu \mathrm{M}$ de $\mathrm{H}_{2} \mathrm{O}_{2}$ was used for 24 hours and 7 days to observe the direct effect of free radicals and the antioxidant action of the additives.

\subsection{Staining}

Cells grown in culture plates were exposed to temporal curves and concentrations of the additives. Cells were then washed of the culture medium and incubated with eosin $0.3 \%$, glacial acetic acid and distilled water for one 
minute. Then, then solution was removed and a phosphate buffer was added. One hundred cells were counted randomly, and those that presented a reddish-orange tone were considered dead, and this percentage was recorded. The methodology was based on [22] and modified.

\subsection{Cellular Proliferation}

Cells were washed with PBS and removed with a trypsin solution 1\%, later they were placed in complete culture medium to inhibit the trypsin. Samples were collected in sterile $15 \mathrm{ml}$ tubes and were centrifuged at $1200 \mathrm{rpm}$ for 10 minutes. Cells in the bottom were suspended in $1 \mathrm{ml}$ of base medium and a sample was taken to be recounted in a haemocytometer diluted 1/100. With this value, samples were seeded in at a density of 100,000 cells per ml, in culture with $1.6 \mathrm{~mm}$ diameter, with $250 \mathrm{ul}$ of medium. This culture was exposed for 24 hours to the additives and the number of cells was recounted by area. The density of cells was recorded as an indicator of the change in cellular proliferation or growth rate, modified from [23].

\subsection{May-Grunwald and Giemsa Staining}

Cells grown in culture plates were exposed to temporal curves and concentration of additives were washed of culture medium and incubated with a PanOptic kit for May-Grunwald and Giemsa staining (Quimica Clinica Aplicada, Spain). Samples were left for 5 seconds in reactive 1, 10 seconds in May-Grunwald reactive and 10 seconds in Giemsa reactive. The plates were washed with ultrapure water and left to be microphotographed with a NIKON Labophot 2 optic microscope and a 519CU 5.OM CMOS camera, modified from [24].

\subsection{Statistical Analysis}

Unless specified, all results including image analysis are presented using the average \pm SEM, we used prism 5 software for the analysis. Statistical comparisons were carried out using ANOVA two way, indicated in the figure legend and Bonferroni test, are used after the analysis (post-test). The sample are exposed to normality test, Shapiro-Wilk, for see how for the distribution is from Gaussian. A probability p less than 0.05 is considered statistically significant.

\section{Results}

\subsection{Silymarin Promotes Cell Proliferation in a Concentration-Response Manner}

The cells are seeded and the beginning of the experitmen observed at time $=0$ (initial condtion) that the number of cells per area upon adding 150 ppm of silymarin. Figure 1(a) shows an example image of the control condition and the cultures treated with $150 \mathrm{ppm}$ silymarin from time $=0$ and at 5 days of exposure, showing an increased number of cells per area in the exposed sample. Figure 1(b) represents a quantification of cell numbers per area at different times, and an increase in cell number can be observed in the treated sample. Figure 1(c) shows the quantified effect of $150 \mathrm{ppm}$ of silymarin. Figure 1(d) shows that there was no deleterious effect on the culture upon being acutely exposed. These data suggest that a dose of $150 \mathrm{ppm}$ does not acutely affect the culture, but it increases chronic cell proliferation.

\subsection{Concentration Dependent Effect and Toxic Model}

We evaluated the concentration-dependent effect for silymarin. For this, we made proliferation curves with different doses of silymarin $(0.1-1000 \mathrm{ppm})$ and we observed the number of cells at the end of the proliferative curve. We observed at 5 days had the maximum proliferation effect and we used the number of the cells at these time for see the effect of the different concentration of the silymarin in the proliferation. In Figure 2(a), a sigmoidal curve is presented of the effect, where $1000 \mathrm{ppm}$ of silymarin is the concentration to generate the median cellular proliferation effect. In mammals, it is described that an increase in metabolism generates oxidative stress conditions, and a manner to induce these states is by using glucose. We did not know what the effect of glucose was on the SHK-1 model, being a culture that is developed at a lower temperature. For this purpose we measured the viability of the culture using MTT at different concentrations of glucose on the external medium for 24 hours. Figure 2(b) shows the development of a curve, indicating that concentrations of $30 \mathrm{mM}$ of glucose generates a significant decrease in the viability of the culture, and can bused as a cellular injury model for oxidative stress. 

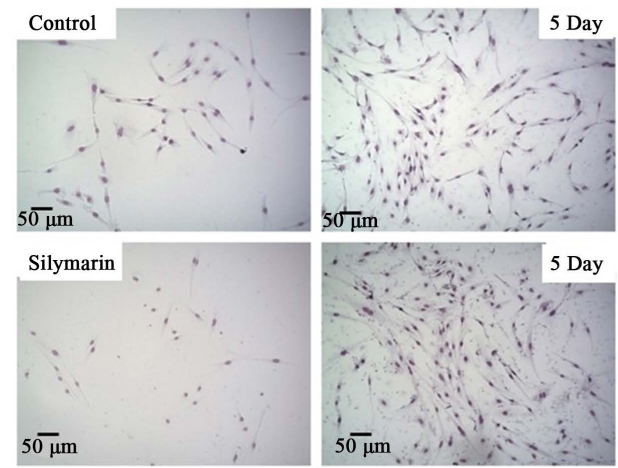

(a)

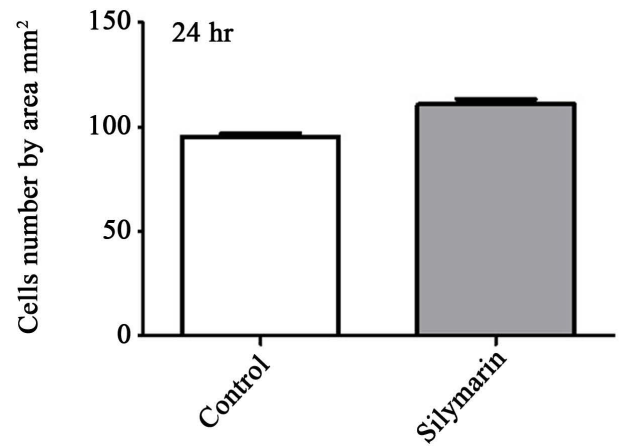

(c)

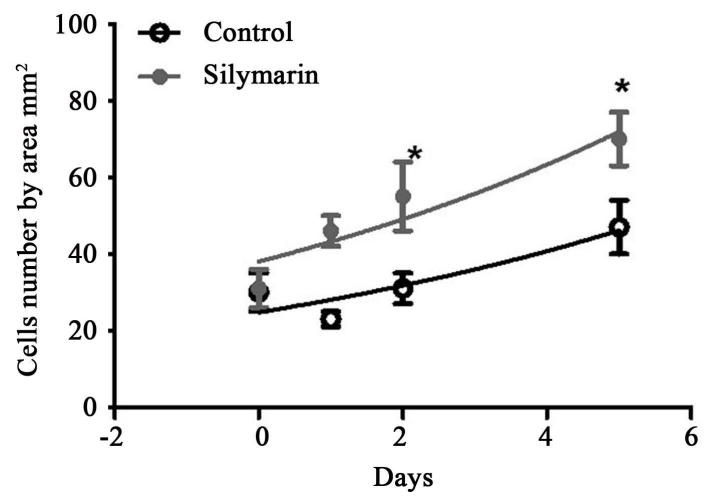

(b)
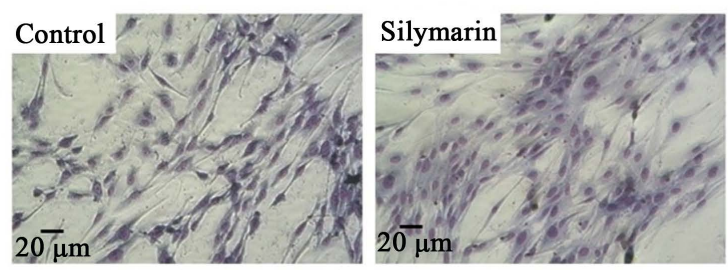

(d)

Figure 1. Effect on cellular proliferation. In (a), example of microphotographs in control, and with silymarin $150 \mathrm{ppm}$ at times 0 and 5 days; (b) quantification of the number of cells after 5 days of culture in absence or presence of silymarin; (c) shows the quantification of the number of cells of the culture exposed to $150 \mathrm{ppm}$ of silymarin after 24 hours; (d) is representative of the quantification at 24 hours of treatment with silymarin $150 \mathrm{ppm}$. The microphotographs are representative of the 5 independent observations. Each bar or point represents (mean \pm SEM), la measurements of at least 5 independent culture and experiments. The asterisk indicates $p<0.05$ (ANOVA).

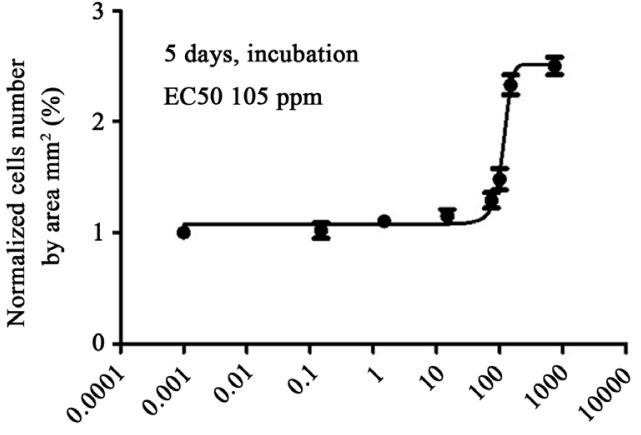

(a)

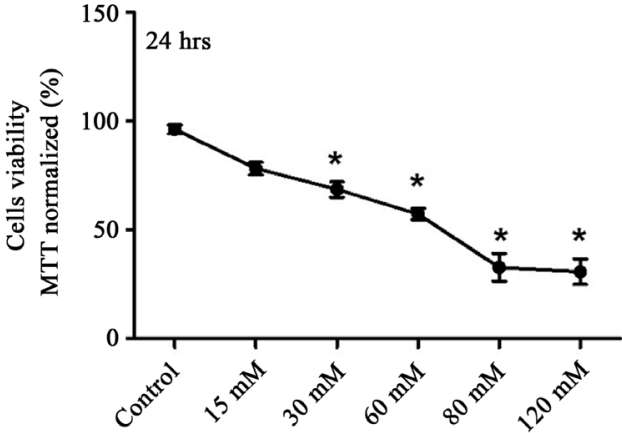

(b)

Figure 2. Doses concentration response. In (a), doses concentration curve, proliferation at 5 days of silymarin 0.1 to 1000 ppm. An EC of 105 ppm is observed for proliferation; (b) shows cellular viability of cell cultures exposed to increasing concentrations of glucose, $15 \mathrm{mM}$ to $120 \mathrm{mM}$, for doses of toxicity at 24 hours of treatment. Each point represents (mean \pm $\mathrm{SEM}$ ), the measurement of at least 3 independent culture and experiments. The asterisk indicates $p<0.05$ (ANOVA).

\subsection{Silymarin Reduces the Effects of High Glucose}

Observing that glucose at $30 \mathrm{mM}$ alters the viability of the cultures, we tested its effect when it was maintained in the presence of 100 ppm silymarin. Figure 3(a) shows samples that were exposed for seven days to high glucose, in the absence and presence of silymarin. Figure 3(b) shows the quantification of the number of cells ex- 


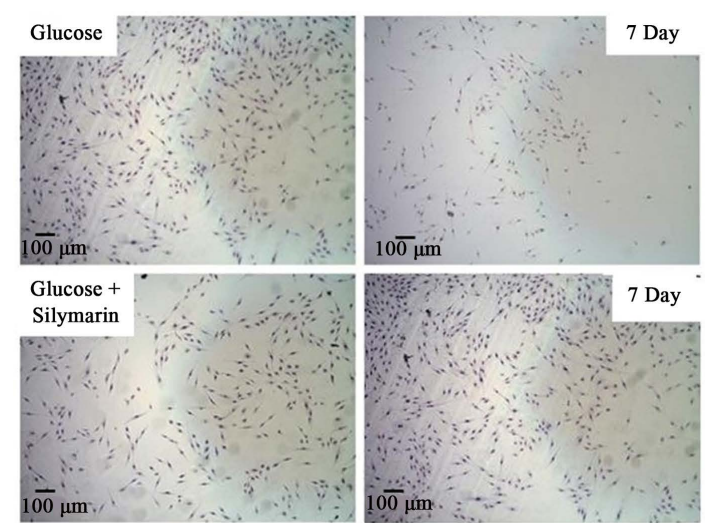

(a)

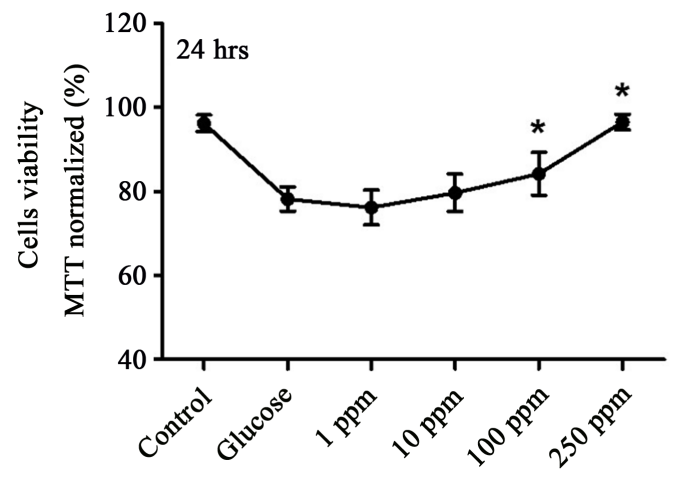

(c)

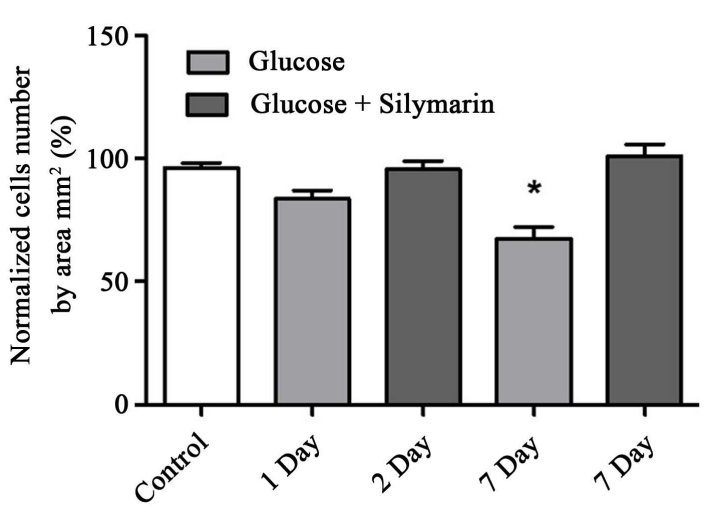

(b)

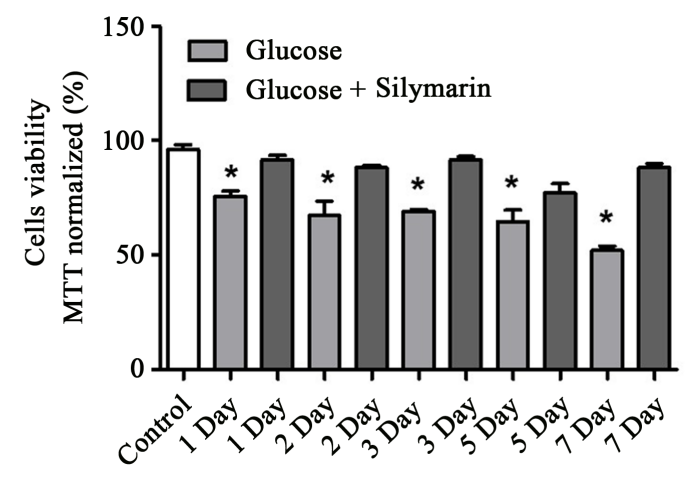

(d)

Figure 3. Cellular protect effect. In (a), example of microphotography $\mathrm{H}_{2} \mathrm{O}_{2} 0.1 \mathrm{mM}$ in the presence or absence of silymarin 100 ppm, 7 days of incubation; (b) demonstrates the quantification of the cells after 7 days of culture in $\mathrm{H}_{2} \mathrm{O}_{2} 0.1 \mathrm{mM}$ in the absence or presence of silymarin 100 ppm; (c) gives the effect of $\mathrm{H}_{2} \mathrm{O}_{2} 0.1 \mathrm{mM}$ after 24 hours on cell viability in the absence or presence of increasing concentrations of silymarin. Microphotography is representative of 6 independent observations made in 6 different cultures. Each bar or point represents (mean \pm SEM), the measurement of at least 6 independent culture and experiments. The asterisk indicates $p<0.05$ (ANOVA).

posed to glucose in absence of precense of silymarin. We observed a reduction on the toxic glucose effect, when exposed to $100 \mathrm{ppm}$ of silymarin. With the objective of determining if the effect is concentration dependent, cultures exposed to $30 \mathrm{mM}$ of glucose for 24 hours, were incubated in incrementing concentrations of silymarin (1 to $250 \mathrm{ppm}$ ). As is shown in Figure 3(c), we observed that very low concentrations of silymarin did not revert the deleterious effects of the glucose, and that values over $100 \mathrm{ppm}$ protect the culture. Upon using the concentration in a chronic form, and evaluating viability by MTT, as is shown in Figure 3(d), we observed that $100 \mathrm{ppm}$ is sufficient to significantly reduce the effect of $30 \mathrm{mM}$ of glucose on the cells. These data suggest that silymarin is capable of reducing an environment of cellular stress generated by high glucose.

\subsection{Silymarin Reduces the Effects of Hydrogen Peroxide}

The metabolic effect, associated to a culture with high glucose, is possible to associate to generation of free radicals that alter the REDOX of the cell. To confirm that silymarin can participate in reduces this effect, we used $\mathrm{H}_{2} \mathrm{O}_{2}$ directly on the culture, to generate an intense toxic effect, suggesting an oxidative stress state. Figure 4(a) shows images of the cultures exposed to $\mathrm{H}_{2} \mathrm{O}_{2} 0.1 \mathrm{mM}$ in the absence and presence of silymarin $100 \mathrm{ppm}$. Figure 4(b) shows a quantification of the chronic effect of the $\mathrm{H}_{2} \mathrm{O}_{2}$ on the culture in the absence and presence of silymarin, observing that after 7 days of co-incubation, the number of cells increased with respect to the culture exposed to $\mathrm{H}_{2} \mathrm{O}_{2}$ in a solitary form, although still less than the control. Upon evaluating the viability of the culture by MTT in acute applications, we observed that silymarin reduces the effects of $\mathrm{H}_{2} \mathrm{O}_{2}$ in a concentration dependent form (Figure 4(c)). Concentrations less than $100 \mathrm{ppm}$ did not significantly reduce the mortality of the 


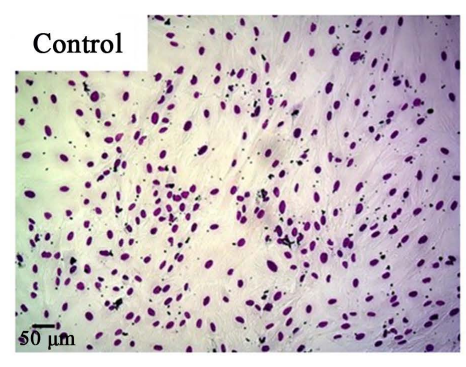

(b)

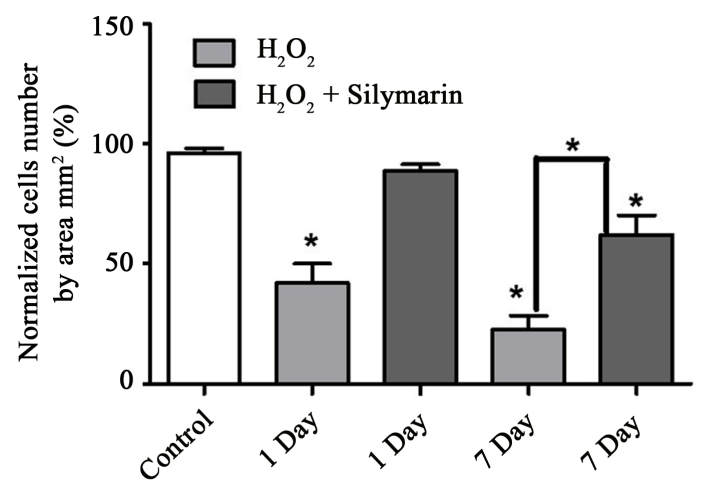

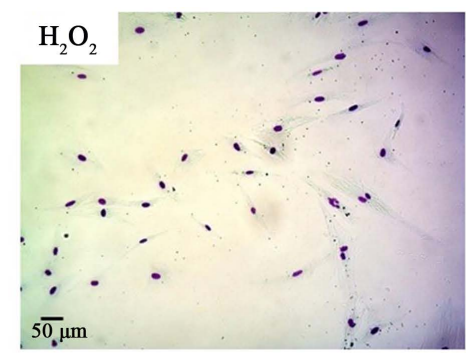

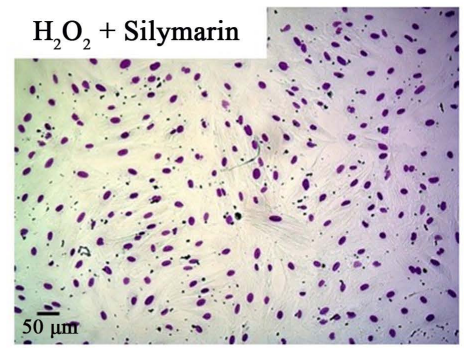

(a)

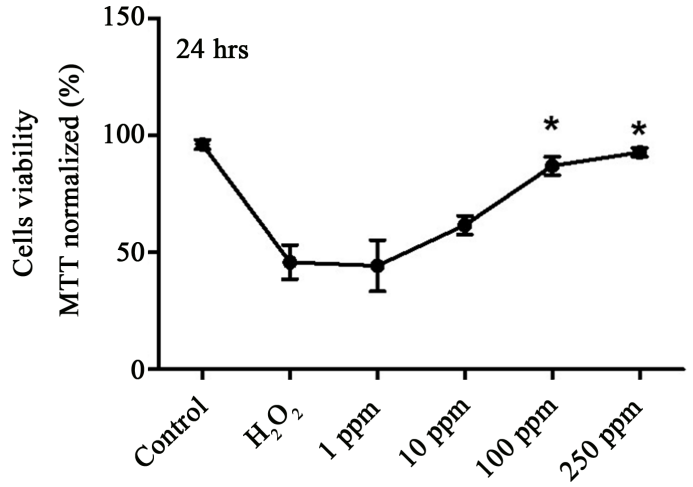

(c)

Figure 4. Cellular protect effect. In (a) example of microphotography $\mathrm{H}_{2} \mathrm{O}_{2} 0.1 \mathrm{mM}$ in the presence or absence of silymarin 100 ppm, 7 days of incubation; (b) demonstrates the quantification of the cells after 7 days of culture in $\mathrm{H}_{2} \mathrm{O}_{2} 0.1 \mathrm{mM}$ in the absence or presence of silymarin 100 ppm; (c) gives the effect of $\mathrm{H}_{2} \mathrm{O}_{2} 0.1 \mathrm{mM}$ after 24 hours on cell viability in the absence or presence of increasing concentrations of silymarin. Microphotography is representative of 6 independent observations made in 6 different cultures. Each bar or point represents (mean \pm SEM), the measurement of at least 6 independent culture and experiments. The asterisk indicates $p<0.05$ (ANOVA).

culture. These date suggest that silymarin acts as protect, reducing the effect of $\mathrm{H}_{2} \mathrm{O}_{2}$ on the cultures in concentrations superior to $100 \mathrm{ppm}$.

\section{Discussion}

The use of cells for the study of additives is a widely used tool in mammalian studies [3]; recently, this type of testing has started to be used in fish, as a way to evaluate procedures [6] and obtain functional information about additives [15]. Our results were obtained using SHK-1 cells exposed to silymarin, an additive used in the salmon industry.

We found that silymarin did not alter cellular viability, and promoted proliferation in this cell line (Figure 1), as well as proliferation in a dose response manner with a value of EC50 of 105 ppm (Figure 2(a)). Silymarin is described as being a good antioxidant in other cellular model [12] and can complete this function in fish [17]. We exposed the effects of silymarin on cultures exposed to high glucose, for made simulation of high oxidative stress (Figure 2(b)), which has been previous described in other cell model [25]. We found that the effects of glucose were reduced when the culture was exposed to $100 \mathrm{ppm}$ silymarin (Figure 3(b)), and this effect in dependent concentration shows that values of $100 \mathrm{ppm}$ of silymarin protect the culture.

Our objective was to determine the direct effect of free radicals on SHK-1 cultures, and if silymarin can reduce their toxicity. So, we exposed the cultures to $0.1 \mathrm{nM}$ of $\mathrm{H}_{2} \mathrm{O}_{2}$ in the presence and absence of $100 \mathrm{ppm}$ silymarin (Figure 4(b)). We observed that the silymarin reduced the mortality of the culture, suggesting a protective effect on oxidative stress conditions. We found that this effect is also concentration dependent (Figure 4(c)), as observed with glucose; values less than $100 \mathrm{ppm}$ did not reduce the effect of $\mathrm{H}_{2} \mathrm{O}_{2}$, increasing mortality in these conditions.

Our findings indicate that concentrations of $100 \mathrm{ppm}$ of silymarin are sufficient to promote cellular division in SHK-1 cells and significantly reduce the toxic effects in cellular injury model. This suggests that in these condi- 
tions, silymarin is an additive which has functions as a cell protector. These results are applicable to the formulation of fish diets, and further studies should focus on the bioavailability of silymarin and the effect it could have on aquaculture.

\section{Acknowledgements}

Financed by the Convenio de Asistencia Técnicas UCT 278-2450 Tonalli 2013. Jorge Parodi received the grant MECESUP UCT 0804. We thank the business SalmoFood-VitaPro, for donating the additives for testing. Rodrigo Sánchez, postgraduate student at the UCT received financing as part of his thesis from SalmoFood-VitaPro.

\section{References}

[1] Wuest, D.M., Harcum, S.W. and Lee, K.H. (2012) Genomics in Mammalian Cell Culture Bioprocessing. Biotechnology Advances, 30, 629-638. http://dx.doi.org/10.1016/j.biotechadv.2011.10.010

[2] Blagodatski, A. and Katanaev, V.L. (2011) Technologies of Directed Protein Evolution in Vivo. Cellular and Molecular Life Sciences, 68, 1207-1214. http://dx.doi.org/10.1007/s00018-010-0610-5

[3] Majors, B.S., Chiang, G.G. and Betenbaugh, M.J. (2009) Protein and Genome Evolution in Mammalian Cells for Biotechnology Applications. Molecular Biotechnology, 42, 216-223. http://dx.doi.org/10.1007/s12033-009-9156-X

[4] Kim, J.Y., Kim, Y.G. and Lee, G.M. (2012) CHO Cells in Biotechnology for Production of Recombinant Proteins: Current State and Further Potential. Applied Microbiology and Biotechnology, 93, 917-930. http://dx.doi.org/10.1007/s00253-011-3758-5

[5] Garcia-Colunga, J. and Miledi, R. (1994) Serotoninergic Agents Block Neuronal Nicotinic Receptors Expressed in Oocytes. FASEB Journal, 8, A107-A107.

[6] Rolland, J.B., Bouchard, D., Coll, J. and Winton, J.R. (2005) Combined Use of the ASK and SHK-1 Cell Lines to Enhance the Detection of Infectious Salmon Anemia Virus. Journal of Veterinary Diagnostic Investigation, 17, 151-157. http://dx.doi.org/10.1177/104063870501700209

[7] Yamaha, E., Saito, T., Goto-Kazeto, R. and Arai, K. (2007) Developmental Biotechnology for Aquaculture, with Special Reference to Surrogate Production in Teleost Fishes. Journal of Sea Research, 58, 8-22. http://dx.doi.org/10.1016/j.seares.2007.02.003

[8] Wu, J.W., Lin, L.C. and Tsai, T.H. (2009) Drug-Drug Interactions of Silymarin on the Perspective of Pharmacokinetics. Journal of Ethnopharmacology, 121, 185-193. http://dx.doi.org/10.1016/j.jep.2008.10.036

[9] Abenavoli, L., Capasso, R., Milic, N. and Capasso, F. (2010) Milk Thistle in Liver Diseases: Past, Present, Future. Phytotherapy Research, 24, 1423-1432. http://dx.doi.org/10.1002/ptr.3207

[10] Yurtcu, E., Iseri, O.D. and Sahin, F.I. (2014) Genotoxic and Cytotoxic Effects of Doxorubicin and Silymarin on Human Hepatocellular Carcinoma Cells. Human and Experimental Toxicology, 33, 1269-1276. http://dx.doi.org/10.1177/0960327114529453

[11] Suh, H.J., Cho, S.Y., Kim, E.Y. and Choi, H.S. (2015) Blockade of Lipid Accumulation by Silibinin in Adipocytes and Zebrafish. Chemico-Biological Interactions, 227, 53-62. http://dx.doi.org/10.1016/j.cbi.2014.12.027

[12] Sherif, I.O. and Al-Gayyar, M.M.H. (2013) Antioxidant, Anti-Inflammatory and Hepatoprotective Effects of Silymarin on Hepatic Dysfunction Induced by Sodium Nitrite. European Cytokine Network, 24, 114-121.

[13] Khazanov, V.A. and Vengerovsky, A.I. (2007) Effect of Silimarin, Succinic Acid, and Their Combination on Bioenergetics of the Brain in Experimental Encephalopathy. Bulletin of Experimental Biology and Medicine, 144, 806-809. http://dx.doi.org/10.1007/s10517-007-0436-9

[14] Razavizadeh, M. and Arj, A. (2012) Comparison of the Therapeutic Effects of Vitamin E and Silymarin in Nonalcoholic Steatohepatitis. Journal of Gastroenterology and Hepatology, 27, 270.

[15] Ahmadi, K., Banaee, M., Vosoghei, A.R., Mirvaghefei, A.R. and Ataeimehr, B. (2012) Evaluation of the Immunomodulatory Effects of Silymarin Extract (Silybum marianum) on Some Immune Parameters of Rainbow Trout, Oncorhynchus mykiss (Actinopterygii: Salmoniformes: Salmonidae). Acta Ichthyologica et Piscatoria, 42, 113-120. http://dx.doi.org/10.3750/AIP2011.42.2.04

[16] Skottova, N., Vecera, R., Urbanek, K., Vana, P., Walterova, D. and Cvak, L. (2003) Effects of Polyphenolic Fraction of Silymarin on Lipoprotein Profile in Rats Fed Cholesterol-Rich Diets. Pharmacological Research, 47, 17-26. http://dx.doi.org/10.1016/S1043-6618(02)00252-9

[17] Shiau, R.J., Shih, P.C. and Wen, Y.D. (2011) Effect of Silymarin on Curcumin-Induced Mortality in Zebrafish (Danio rerio) Embryos and Larvae. Indian Journal of Experimental Biology, 49, 491-497. 
[18] Banaee, M., Sureda, A., Mirvaghefi, A.R. and Rafei, G.R. (2011) Effects of Long-Term Silymarin Oral Supplementation on the Blood Biochemical Profile of Rainbow Trout (Oncorhynchus mykiss). Fish Physiology and Biochemistry, 37, 885-896. http://dx.doi.org/10.1007/s10695-011-9486-z

[19] Jia, R., Cao, L.P., Du, J.L., Xu, P., Jeney, G. and Yin, G.J. (2013) The Protective Effect of Silymarin on the Carbon Tetrachloride $\left(\mathrm{CCl}_{4}\right)$-Induced Liver Injury in Common Carp (Cyprinus carpio). In Vitro Cellular \& Developmental Biology-Animal, 49, 155-161.

[20] Malekinejad, H., Taheri-Brujerdi, M., Janbaz-Acyabar, H. and Amniattalab, A. (2012) Silymarin Regulates HIF-1 Alpha and iNOS Expression in the Brain and Gills of Hypoxic-Reoxygenated Rainbow Trout Oncorhynchus mykiss. Aquatic Biology, 15, 261-273. http://dx.doi.org/10.3354/ab00427

[21] Jofre, I., Gomez, P.N., Parodi, J., Romero, F. and Salazar, R. (2013) Chilean Crude Extract of Ruta graveolens Generates Vasodilatation in Rat Aorta at Subtoxic Cellular Concentrations. Advances in Bioscience and Biotechnology, 4, 8.

[22] Navarrete, G.P., Alvarez, J.G., Parodi, J., Romero, F. and Sánchez, R. (2012) Effect of Aracnotoxin from Latrodectus mactans on Bovine Sperm Function: Modulatory Action of Bovine Oviduct Cells and Their Secretions. Andrologia, 44, 764-771.

[23] Parodi, J., Flores, C., Aguayo, C., Rudolph, M.I., Casanello, P. and Sobrevia, L. (2002) Inhibition of Nitrobenzylthioinosine-Sensitive Adenosine Transport by Elevated D-Glucose Involves Activation of P2Y2 Purinoceptors in Human Umbilical Vein Endothelial Cells. Circulation Research, 90, 570-577. http://dx.doi.org/10.1161/01.RES.0000012582.11979.8B

[24] Flores, C., Rojas, S., Aguayo, C., Parodi, J., Mann, G., Pearson, J.D., Casanello, P. and Sobrevia, L. (2003) Rapid Stimulation of L-Arginine Transport by D-Glucose Involves p42/44(Mapk) and Nitric Oxide in Human Umbilical Vein Endothelium. Circulation Research, 92, 64-72. http://dx.doi.org/10.1161/01.RES.0000048197.78764.D6

[25] Robertson, R.P., Harmon, J., Tran, P.O., Tanaka, Y. and Takahashi, H. (2003) Glucose Toxicity in Beta-Cells: Type 2 Diabetes, Good Radicals Gone Bad, and the Glutathione Connection. Diabetes, 52, 581-587. http://dx.doi.org/10.2337/diabetes.52.3.581 